\title{
Analisis Sifat Fisika dan Kimia Lignin Tandan Kosong Kelapa Sawit asal Desa Sape, Kabupaten Sanggau, Kalimantan Barat
}

\author{
Siti Suhartati, Rachmat Puspito, Fikri Rizali, Dian Anggraini \\ Akademi Kimia Analisis Caraka Nusantara, Jakarta \\ Email: sitisuhartati@gmail.com
}

\begin{abstract}
Abstrak
Telah dilakukan analisis sifat fisika dan kimia lignin tandan kosong kelapa sawit (TKKS) asal Desa Sape, Kabupaten Sanggau, Kalimantan Barat. Penelitian ini bertujuan untuk mengekstraksi dan mengisolasi lignin TKKS, menentukan densitas, dan viskositas lindi hitam TKKS serta menganalisis kemurnian, kadar air dan kadar abu isolat lignin. Proses refluks digunakan untuk mengekstraksi TKKS menghasilkan lindi hitam, sedangkan isolasi lignin dilakukan menggunakan metode organosolv untuk menghasilkan isolat lignin. Hasil analisis menunjukkan densitas dan viskositas lindi hitam TKKS masing-masing diperoleh hasil sebesar 0.9658 $\mathrm{g} / \mathrm{mL}$ dan $1.4565 \mathrm{Ns} / \mathrm{m}^{2}$. Hasil analisis kemurnian isolat lignin, kadar air dan kadar abu lignin TKKS masingmasing sebesar $64.64 \%, 3.07 \%$ dan $30.34 \%$. Data hasil analisis ini mennjadi dasar pemanfaatan lignin TKKS di beberapa industri berbasis lignin.
\end{abstract}

Kata kunci: Sifat fisika dan kimia, lignin, TKKS

\begin{abstract}
Analysis of the physical and chemical properties of palm empty fruit bunches (EFB) lignin from Sape village in Sanggau, West Borneo has been done. This research was aimed to find extract and isolate the EFB lignin, to determine density, and viscosity of black liquor containing EFB lignin and to find the purity, moisture content and ash content of isolated EFB lignin. Black liquor was extracted by using reflux process and the lignin was isolated by using organosolv process. The result showed that the density and viscosity of the black liquor was $0.9658 \mathrm{~g} / \mathrm{mL}$ and $1.4565 \mathrm{Ns} / \mathrm{m}^{2}$, respectively. The isolated lignin isolated has purity about $64.64 \%$ with moisture content about $3.07 \%$ and the ash content about $30.34 \%$. The data from this analysis became the basis of utilization of lignin TKKS in some lignin-based industries.
\end{abstract}

Key words: Analysis of physical and chemical properties, lignin, EFB

DOI: http://dx.doi.org/10.15408/jkv.v2i1.3102 


\section{PENDAHULUAN}

Kelapa sawit merupakan komoditi perkebunan penghasil minyak sawit (Crude palm oil, CPO) yang menjanjikan. Pemerintah mendukung komoditi tersebut dengan membangun dan memperluas lahan perkebunan kelapa sawit hingga 10.955.231 $\mathrm{Ha}$ di tahun 2014 dengan total produksi CPO mencapai 29.344.479 Ton (Direktorat Jenderal Perkebunan, 2014). Setiap produksi kelapa sawit menghasilkan limbah berupa tandan kosong kelapa sawit $23 \%$, cangkang $8 \%$, serat $12 \%$, dan limbah cair $66 \%$. Limbah tandan kosong sawit pada tahun 2010 mencapai 5.050.367,6 ton dan pada tahun 2011 mencapai 5.176.842,53 ton (Yuliani, 2012). Kandungan utama TKKS adalah selulosa, hemiselulosa dan lignin.

Salah satu wilayah pengembangan perkebunan kelapa sawit di Indonesia adalah Desa Sape, Kabupaten Sanggau, Kalimantan Barat. Limbah TKKS di wilayah ini lebih sering dibakar petani karena mempersempit luas lahan perkebunan. Pemanfaatan kandungan selulosa dari limbah yang dihasilkan memiliki nilai ekonomis yang rendah karena hanya digunakan sebagai pupuk alami dan mulsa kebun tanpa pengembangan produk yang lebih bernilai tinggi. Sejauh ini, penelitian tentang limbah TKKS lebih mengedepankan penggunaan selulosa sebagai bahan olahan seperti adsorben (Rahmalia et al., 2006; Nurrohmi, 2011), pembuatan pulp (Roliadi, 2009), pupuk organik (Ningtyas dan Astuti 2010) dan selulosa asetat (Gaol et al., 2013). Pemanfaatan lignin yang terkandung dalam limbah TKKS belum dimanfaatkan secara maksimal baik di masyarakat maupun industri.

Lignin merupakan polimer alami yang memiliki fungsi utama sebagai perekat pada lapisan tumbuhan. Lignin memiliki gugus fungsi seperti hidroksi, karbonil dan metoksi serta memiliki kelarutan yang rendah terhadap air sehingga berpotensi untuk dimanfaatkan sebagai perekat, plastik biodegradable dan surfaktan pada sistem Enhanced Oil Recovery (EOR).

Untuk memanfaatkan lignin limbah TKKS dari Desa Sape, Kabupaten Sanggau pada sektor industri di atas, diperlukan data sifat fisika dan kimia lignin yang dapat menjadi acuan untuk banyak jenis penelitian di bidang lignin TKKS. Hal ini mengingat bahwa setiap daerah memiliki karakteristik lignin
TKKS yang khas akibat pengaruh kondisi lingkungan sekitar. Sifat fisika dan kimia yang dianalisis yaitu densitas dan viskositas lignin terlarut (lindi hitam) serta analisis kemurnian, kadar air dan kadar abu lignin TKKS.

\section{METODE PENELITIAN}

\section{Alat dan Bahan}

Alat yang digunakan adalah desikator, erlenmeyer, kondensor, labu boiling, piknometer, stirring hotplate, kertas saring, oven, tanur dan viskometer Ostwald. Bahan yang digunakan dalam penelitian ini adalah limbah TKKS dari Desa Sape, Kabupaten Sanggau, Kalimantan Barat, akuades, asam sulfat, etanol dan natrium hidroksida.

\section{Ekstraksi dan Isolasi Lignin TKKS}

Lindi hitam merupakan cairan yang dihasilkan dalam proses delignifikasi limbah TKKS melalui proses ekstraksi. Sampel TKKS dipotong kecil-kecil dan dikeringkan terlebih dahulu sebelum dilakukan ekstraksi. Proses ekstraksi dilakukan menggunakan metode refluks dengan memanaskan sampel TKKS selama 1 jam. Pelarut yang digunakan dalam proses ini adalah campuran etanol:akuades 1:1 (v/v) pada $\mathrm{pH} 8$ dengan penambahan $\mathrm{NaOH}$. Setelah dingin, sampel disaring untuk mendapatkan filtrat (lindi hitam).

Lindi hitam diisolasi menggunakan proses organosolv untuk mendapatkan isolat lignin. Lindi hitam ditambahkan dengan akuades dengan perbandingan lindi hitam : akuades 1:7 (v/v). Lindi hitam diasamkan hingga $\mathrm{pH} 2$ menggunakan asam sulfat kemudian diaduk menggunakan magnetic stirer selama 30 menit pada suhu $60{ }^{\circ} \mathrm{C}$.

Lindi hitam diendapkan selama 30 menit kemudian disaring dan dicuci dengan akuades pH 2 yang dibuat dengan menambahkan sedikit demi sedikit $\mathrm{H}_{2} \mathrm{SO}_{4}$ kedalam akuades hingga $\mathrm{pH}$ 2. Padatan yang diperoleh dikeringkan dalam oven suhu $60{ }^{\circ} \mathrm{C}$ diikuti penyimpanan di dalam desikator. Padatan yang dihasilkan disebut isolat lignin yang akan dianalisis kemurnian, kadar air dan kadar abu.

\section{Pengujian Densitas Lindi Hitam}

Densitas lindi hitam dianalisis menggunakan piknometer ukuran $10 \mathrm{~mL}$. Piknometer yang telah diketahui massa kosong diisi dengan lindi hitam kemudian ditimbang untuk mengetahui massa lindi hitam. Sebagai perbandingan, digunakan data massa akuades 
dan densitas air pada suhu $28{ }^{\circ} \mathrm{C}$. Densitas diukur dengan pengulangan sebanyak tiga kali.

\section{Pengujian Viskositas Lindi Hitam}

Viskositas lindi hitam ditentukan menggunakan viskometer Oswald. Viskositas ditentukan dengan membandingkan waktu alir lindi hitam dengan waktu alir akuades pada suhu $28{ }^{\circ} \mathrm{C}$. Lindi hitam dialirkan ke dalam viskometer sesuai dengan tanda batas alir yang terdapat pada viskometer. Waktu alir diukur dengan pengulangan sebanyak tiga kali.

\section{Pengujian Kemurnian Isolat Lignin}

Pengujian kemurnian lignin ditentukan dengan membandingkan berat lignin murni dengan lignin awal. Lignin kering dilarutkan dengan $\mathrm{H}_{2} \mathrm{SO}_{4} \quad 72 \%$ dan didiamkan selama 2 jam dalam wadah tertutup. Sampel diencerkan dengan akuades dan direfluks selama 1 jam. Endapan yang terbentuk disaring, dicuci dengan akuades bebas asam kemudian dikeringkan dan ditimbang. Kemurnian lignin ditentukan berdasarkan persamaan berikut:

$\%$ kemurnian $=\frac{\text { beral lignim wurri }}{\text { berat. lignin }} \times 100 \%$

\section{Pengujian Kadar Air Isolat Lignin}

Pengujian kadar air digunakan untuk mengetahui jumlah air yang masih terikat pada isolat lignin. Kadar air ditentukan menggunakan metode oven dengan melakukan pengeringan 0.1 gram isolat lignin selama 3 jam pada suhu $105{ }^{\circ} \mathrm{C}$ kemudian didinginkan di dalam desikator. Pengeringan ini dilakukan berulang hingga berat isolat lignin konstan. Kadar air isolat lignin ditentukan berdasarkan persamaan berikut:

$$
\% \text { kadar air }=\frac{b-c}{b} \times 100 \%
$$

dengan $b$ merupakan berat cawan dan isolat lignin sebelum dikeringkan dalam oven (gram), sedangkan $c$ merupakan berat cawan dan isolat lignin setelah dikeringkan dalam oven (gram).

\section{Pengujian Kadar Abu Isolat Lignin}

Pengujian kadar abu digunakan untuk mengetahui zat sisa hasil pembakaran suatu bahan organik. Kadar abu isolat lignin ditentukan dengan membakar 0.1 gram lignin kering dalam tanur pada suhu $550{ }^{\circ} \mathrm{C}$. Kadar abu pada isolat lignin ditentukan berdasarkan persamaan berikut:

$\%$ kadar abu $=\frac{\text { berat akhir }}{\text { berat awal }} \times 100 \%$

dimana berat awal sampel dikoreksi terhadap kadar air yang diperoleh dalam perhitungan.

\section{HASIL DAN PEMBAHASAN}

Limbah TKKS merupakan sisa hasil produksi CPO yang masih dapat dimanfaatkan. Pemanfaatan limbah TKKS akan mengurangi efek pencemaran lingkungan. Lignin dari limbah TKKS asal Desa Sape, Kabupaten Sanggau, Kalimantan Barat sangat potensial untuk diolah dan dikembangkan menjadi produk dengan nilai ekonomis yang lebih tinggi. Hal ini didasarkan pada data analisis sifat fisika dan kimia lignin TKKS yang menunjukkan keunggulan dibandingkan dengan lignin yang berasal dari tumbuhan lain.

Lignin diekstraksi menggunakan campuran pelarut etanol-akuades dengan penambahan $\mathrm{NaOH}$. Etanol digunakan sebagai pelarut disebabkan oleh kemudahan dalam pemisahan selulosa TKKS dengan senyawa lain. Selain itu, penggunaan etanol memberi dampak lingkungan yang rendah, tidak mengubah struktur zat terlarut, recovery pelarut relatif mudah dan produk samping yang dihasilkan dapat dimanfaatkan lebih lanjut (Susanto, 1999).

Proses ekstraksi dilakukan pada $\mathrm{pH} 8$ dengan penambahan $\mathrm{NaOH}$. Penambahan pelarut $\mathrm{NaOH}$ dilakukan karena lignin memiliki sifat mudah larut dalam kondisi basa. Hal ini menyebabkan lignin pada sampel TKKS dapat diekstraksi ke dalam pelarut campuran etanol-akuades. Selain itu, larutan $\mathrm{NaOH}$ juga berfungsi sebagai katalis pada proses ekstraksi ini. Proses ekstraksi lignin dari sampel TKKS menghasilkan lignin terlarut yang disebut dengan lindi hitam dengan kadar lignin rata-rata $6.735 \mathrm{~g} / \mathrm{L}$.

\section{Densitas dan Viskositas Lindi Hitam}

Densitas atau massa jenis merupakan besaran kerapatan massa zat yang dinyatakan dalam berat zat per satuan volume. Setiap zat memiliki densitas yang khas yang menunjukkan karakter dari zat tersebut. Nilai densitas lindi hitam dianalisis dengan membandingkan data densitas air pada suhu 28 ${ }^{\circ} \mathrm{C}$. 
Tabel 1. Densitas lindi hitam

\begin{tabular}{|c|c|c|c|}
\hline \multirow{2}{*}{ Percobaan } & \multirow{2}{*}{$\begin{array}{c}\text { Densitas } \\
(\mathrm{g} / \mathrm{mL})\end{array}$} & \multicolumn{2}{|c|}{$\begin{array}{c}\text { Densitas Sampel } \\
\text { Lain }(\mathrm{g} / \mathrm{mL})\end{array}$} \\
\hline & & $\begin{array}{l}\text { Sampel } \\
\text { A }^{*}\end{array}$ & $\begin{array}{l}\text { Sampel } \\
\text { B }^{* *}\end{array}$ \\
\hline 1 & 0.9675 & & \\
\hline 2 & 0.9660 & & \\
\hline 3 & 0.9639 & & \\
\hline Rata-rata & 0.9658 & 0.9308 & 1.02 \\
\hline
\end{tabular}

Hasil pengujian densitas lindi hitam TKKS dapat dilihat pada Tabel 1. Rata-rata densitas lindi hitam TKKS yaitu $0.9658 \mathrm{~g} / \mathrm{mL}$. Nilai tersebut tidak jauh berbeda dengan penelitian sebelumnya oleh Suhartati (2009) dan Syamsudin dkk (2007) masing-masing sebesar $0.9308 \mathrm{~g} / \mathrm{mL}$ dan $1.02 \mathrm{~g} / \mathrm{mL}$. Data densitas sangat diperlukan dalam pengukuran viskositas lindi hitam dan pengaruhnya terhadap daya rekat perekat komersial seperti urea formaldehida maupun fenol formaldehida termodifikasi lindi hitam (Susilowati et al., 2013).

Tabel 2. Viskositas lindi hitam (Suhu $\left.28^{\circ} \mathrm{C}\right)$

\begin{tabular}{lcc}
\hline Percobaan & $\begin{array}{c}\text { Viskositas } \\
\left(\mathbf{N s} / \mathbf{m}^{\mathbf{2}}\right)\end{array}$ & $\begin{array}{c}\text { Viskositas Sampel } \\
\text { Lain }\left(\mathbf{N s} / \mathbf{m}^{\mathbf{2}}\right)\end{array}$ \\
\hline 1 & 1.4753 & \\
2 & 1.4342 & \\
3 & 1.4600 & \\
Rata-rata & 1.4565 & 2.0753 \\
\hline
\end{tabular}

Viskositas merupakan ukuran kekentalan fluida yang menyatakan besar kecilnya gesekan di dalam suatu fluida. Semakin besar viskositas lindi hitam, semakin besar hambatan alir dalam lindi hitam tersebut. Pengukuran viskositas relatif lindi hitam dilakukan dengan menggunakan viskometer Oswald. Lindi hitam dan akuades (fluida pembanding) diukur pada suhu yang sama yaitu $28^{\circ} \mathrm{C}$.

Pemanfaatan lindi hitam sebagai perekat urea formaldehida pada kayu lapis dipengaruhi oleh nilai viskositas. Viskositas yang terlalu tinggi menyebabkan perekat lebih cepat mengeras dan sulit menembus pori-pori kayu lapis. Hal ini mengakibatkan menurunnya kekuatan rekat urea formaldehida tersebut. Oleh karena itu, nilai viskositas menjadi salah satu parameter yang penting dalam pengukuran sifat lindi hitam. Berdasarkan Tabel 2, lindi hitam TKKS memiliki viskositas yang berbeda dengan penelitian lignin asal Kabupaten
Mempawah yang dilakukan oleh Suhartati (2009) sebesar $2.0753 \mathrm{Ns} / \mathrm{m}^{2}$. Perbedaan nilai viskositas lindi hitam tiap daerah dapat dipengaruhi oleh perbedaan kondisi lingkungan tempat tumbuh tanaman.

\section{Isolasi Lignin}

Lindi hitam yang dihasilkan kemudian diisolasi untuk mendapatkan isolat lignin. Lignin merupakan polimer berbentuk tiga dimensi yang mempunyai basis unit fenilpropana dan gugus-gugus fungsional hidroksi, karbonil dan metoksi. Unsur-unsur struktural lignin dihubungkan oleh ikatan karbon-karbon dan eter untuk membentuk jaringan tiga-dimensi dengan polisakarida dan hemiselulosa dalam jaringan sel tumbuhan (Chuah and Ibrahim, 2004).

Lindi hitam ditambahkan akuades dengan perbandingan lindi hitam-akuades 1:7 $(\mathrm{v} / \mathrm{v})$ untuk mengurangi kelarutan lignin sehingga lebih mudah mengendap dan terpisah dari pelarut. Proses isolasi dibantu dengan penambahan $\mathrm{H}_{2} \mathrm{SO}_{4}$ untuk membentuk kondisi asam selama reaksi berlangsung. Lignin memiliki sifat tidak larut dalam kondisi asam dan larut dalam kondisi basa. Penambahan asam menyebabkan terjadinya protonasi gugus eter yang diikuti dengan pelepasan molekul alkohol menghasilkan sistem benzilium dan oksonium. Reaksi kondensasi dapat terjadi antara ion-ion benzilium dengan nukleofil menghasilkan isolat lignin (Anisa, 2009). Proses pengendapan isolat lignin ditandai dengan pembentukan partikel dengan ukuran lebih besar dan menggumpal di dalam lindi hitam.

\section{Analisis Kemurnian, Kadar Air dan Kadar Abu Isolat Lignin TKKS}

Isolat lignin dianalisis kemurnian, kadar air dan kadar abu. Kemurnian lignin ditentukan dengan membandingkan berat kering lignin murni dengan lignin awal. Analisis kemurnian lignin didasarkan pada perbedaan kelarutan lignin dengan senyawa kontaminan apabila dilarutkan dalam $\mathrm{H}_{2} \mathrm{SO}_{4} 72 \%$ (Anisa, 2009). Senyawa kontaminan yang umum terdapat dalam sampel lignin adalah sisa selulosa atau produk degradasi selulosa. Penambahan asam kuat dengan konsentrasi tinggi seperti $\mathrm{H}_{2} \mathrm{SO}_{4}$ $72 \%$ akan menyebabkan selulosa larut dan meninggalkan lignin murni yang mengendap pada kondisi asam. Kemurnian lignin yang didapat dalam penelitian ini adalah $64.64 \%$. Nilai kemurnian ini cukup tinggi, namun lebih 
rendah dari penelitian yang dilakukan Anisa (2009) sebesar 70\%, Simatupang dkk (2012) sebesar 84.21\% dan Suryani dkk (2008) sebesar $88.39 \%$. Hal ini dapat terjadi karena adanya zat lain yang terkandung di dalam isolat lignin seperti mineral dan air. Hal ini sesuai dengan data kadar air dan kadar abu pada isolat lignin TKKS yang juga dianalisis dalam penelitian ini yaitu masing-masing sebesar $3.07 \%$ dan $30.34 \%$.

Kadar air yang rendah pada lignin dikarenakan sifat lignin yang hidrofobik (tahan air). Sifat ini menyebabkan lignin tidak mudah mengikat air. Sifat hidrofobik lignin dan turunannya dapat dimanfaatkan dalam pembuatan surfaktan pada proses kilang minyak dengan sistem Enhanced Oil Recovery (EOR).

Kadar abu pada isolat lignin cukup tinggi yaitu $30.34 \%$ dan lebih tinggi dari hasil penelitian Syamsudin et al., (2007) dengan kadar abu $12.1 \%$. Perbedaan jumlah dan komposisi abu tergantung dari jenis sampel yang digunakan. Tingginya kadar abu lignin TKKS mendukung penggunaan TKKS dalam pembuatan pupuk tanaman seperti yang dilakukan oleh sebagian masyarakat di Desa Sape.

\section{SIMPULAN}

Densitas dan viskositas lindi hitam yang diekstraksi dari TKKS asal Desa Sape, Kabupaten Sanggau, Kalimantan Barat masing-masing sebesar $0.9658 \mathrm{~g} / \mathrm{mL}$ dan $1.4565 \mathrm{Ns} / \mathrm{m}^{2}$. Lignin diisolasi dari lindi hitam menghasilkan isolat lignin dengan kemurnian $64.64 \%$ serta kadar air dan kadar abu masingmasing sebesar $3.07 \%$ dan $30.34 \%$. Data hasil analisis ini mennjadi dasar pemanfaatan lignin TKKS di beberapa industri berbasis lignin.

\section{SARAN}

Perlu penelitian lanjutan tentang karakteristik lignin TKKS asal Desa Sape, Kabupaten Sanggau, Kalimantan Barat menggunakan alat instrumentasi seperti spektrofotometer sinar ultraviolet/tampak untuk mengetahui karakteristik serapan maksimum lignin dan spektrofotometer infra merah untuk mengetahui gugus fungsi lignin.

\section{DAFTAR PUSTAKA}

Anisa. 2009. Karakterisasi lignin dari lindi hitam tandan kosong sawit menggunakan $\mathrm{H}_{3} \mathrm{PO}_{4}$ dan $\mathrm{H}_{2} \mathrm{SO}_{4}$ dengan variasi suhu dan konsentrasi. Skripsi, Universitas Tanjungpura.

Chuah SB, Ibrahim MNM. 2004. Characterization of lignin precipitated from the soda black liquor of oil palm empty fruit bunch fibers by various mineral acids. AJSTD. 21:5767.

Direktorat Jenderal Perkebunan. 2014. Luas Areal, produksi dan produktivitas perkebunan di Indonesia. Jakarta, Ditjenbun.

Gaol MRLL, Sitorus R, Surya YSI, Manurung R. 2013. Pembuatan selulosa asetat dari $\alpha$ selulosa tandan kosong kelapa sawit. J. Tek. Kimia USU. 2(3).

Ningtyas VA, Astuti LY. 2010. Pemanfaatan tandan kosong kelapa sawit sisa media jamur merang (Volvariella volvacea) sebagai pupuk organik dengan penambahan aktivator effective microorganism EM-4. Skripsi, ITS Library.

Nurrohmi O. 2011. Biomassa tandan kosong kelapa Sawit (TKKS) sebagais adsorben ion logam $\mathrm{Cd}^{2+}$. Skripsi, Universitas Indonesia.

Rahmalia W, Yulistira F, Ningrum J, Qurbaniah M, Ismadi M. 2006. Pemanfaatan potensi tandan kosong kelapa sawit (Elais guineensis Jacq.) sebagai bahan dasar Caktif untuk Adsorpsi Logam Perak dalam Larutan. PKM-3-13-1 Universitas Tanjungpura.

Roliadi H. 2009. Pembuatan dan kualitas karton dari campuran pulp tandan kosong kelapa sawit dan limbah padat organik industri pulp. Bogor: Pusat Penelitian dan Pengembangan Hasil Hutan.

Simatupang H, Nata A, Herlina N. 2012. Studi isolasi dan rendemen lignin dari tandan kosong kelapa sawit (TKKS). Jurnal Teknik Kimia USU. 1(1).

Suhartati S. 2009. Pengujian kekuatan rekat urea formaldehida termodifikasi lindi hitam tandan kosong sawit. Skripsi, Universitas Tanjungpura. 
Suryani A, Mangunwidjaja D, Hambali E, Anwar K. 2008. Proses optimasi suhu dan konsentrasi sodium bisulfit $\left(\mathrm{NaHSO}_{3}\right)$ pada pembuatan sodium lignosulfonat berbasis tandan kosong kelapa sawit (TKKS). J. Tek. Ind. Pert. 18(2): 127-137.

Susanto H. 1999. Simultaneous hydrolisis of hemicellolose and delignification of oil palm empty bunch. Tesis, Departement of Chemical Engineer Institut Teknologi Bandung.
Susilowati, Munandar S, Edahwat L. 2013. Pemanfaatan lignin dari limbah kulit kakao menjadi perekat. J.Tek.Kim. 8(1): 22-26.

Syamsudin, Purwati S, Rostika I. 2007. Pemanfaatan campuran limbah padat dengan lindi hitam dari industri pulp dan kertas sebagai bahan biobriket. Berita Selulosa. 42(2):67-74.

Yuliani. 2012. Kualitas papan partikel tandan kosong sawit (Elais guineensis Jacq.) menggunakan perekat likuida dengan penambahan resorsinol. Skripsi, Institut Pertanian Bogor. 